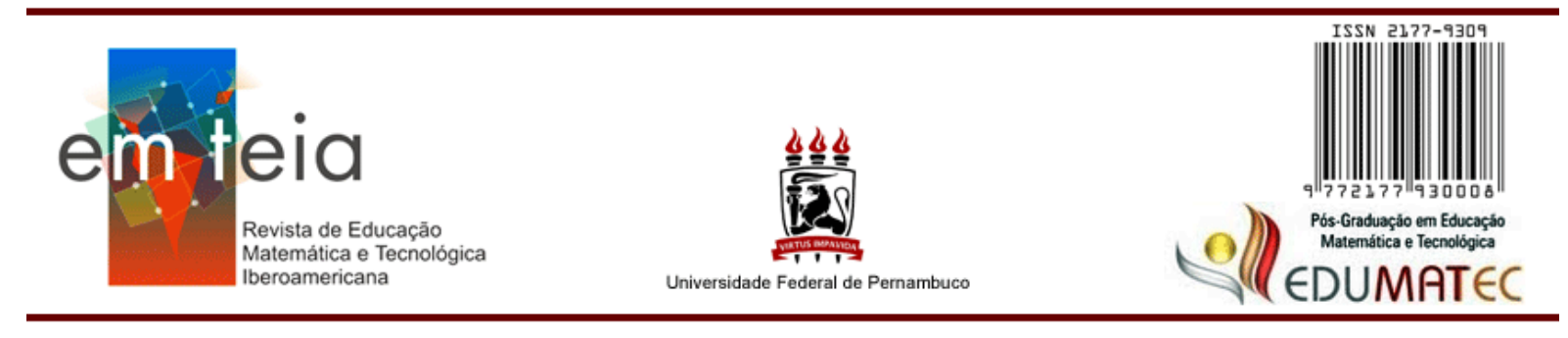

\title{
FORMULAÇÃO DE PROBLEMAS DO CAMPO CONCEITUAL MULTIPLICATIVO NO ENSINO FUNDAMENTAL: UMA PRÁTICA INSERIDA NA METODOLOGIA DE RESOLUÇÃO DE PROBLEMAS
}

\author{
Renan Oliveira Altoé \\ Mestre em Educação em Ciências e Matemática - IFES \\ renan.o.altoe@gmail.com \\ Instituto Federal de Educação, Ciência e Tecnologia do Espírito Santo - IFES \\ Vitória - ES \\ ORCID - http://orcid.org/0000-0003-3634-4166
}

Resolver problemas tem sido considerado o alicerce da metodologia de Resolução de Problemas. Nesse enfoque, os professores são responsáveis em propor os problemas e, os discentes, em resolvê-los. Entretanto, acreditamos ser importante que se fizessem novas reflexões referentes à proposição de problemas em sala de aula, inserindo, neste caso, a possibilidade dos estudantes de formularem problemas de matemática.

Diante desse contexto, a pesquisa de Mestrado em Educação em Ciências e Matemática, aqui relatada, teve com objetivo investigar contribuições de atividades pautadas na Formulação de Problemas para o ensino de conceitos de multiplicação e divisão nos anos iniciais do ensino fundamental. Foi desenvolvida com 28 estudantes de um $5^{\circ}$ ano, de uma Escola Estadual de Ensino Fundamental e Médio do município de Vargem Alta - ES, envolvendo, também, a participação colaborativa da professora regente. Serviram como instrumentos de coleta de dados gravações em áudio e vídeo, registros em diário de bordo do pesquisador, entrevista e grupo focal.

No primeiro capítulo, intitulado "Aporte metodológico da pesquisa", abordamos a respeito da Engenharia Didática (tipo clássica ou de primeira geração), com destaque para os aspectos teóricos e metodológicos, com base nos estudos Pais, Almouloud e Coutinho e Almouloud e Silva. Afirmamos a natureza qualitativa da pesquisa, combinada com um desenho metodológico de caráter experimental, uma vez que comtempla a dimensão teórica e 
experimental da pesquisa em didática. A Engenharia Didática segue quatro fases: 1) Análises preliminares; 2) Concepção e análise a priori; 3) Aplicação de uma sequência didática e 4) Análise a posteriori e a avaliação. Em nossa pesquisa, modificando a nomenclatura da terceira fase para "Aplicação de uma sequência de atividades", uma vez que não construímos uma sequência didática propriamente dita, mas cinco propostas de Formulação de Problemas.

No segundo capítulo, designado de "Primeira fase: análises preliminares", elaboramos um quadro teórico e submetemos o objeto de pesquisa a análises, constatando possíveis concepções dos seus envolvidos, compreendendo as condições da realidade sobre a qual a experiência seria realizada. Assim, nesse capítulo, apresentamos: i) estudos (revisão de literatura) sobre Formulação de Problemas em Matemática, produzidos em âmbito nacional e internacional; ii) estudos teóricos sobre Formulação de Problemas em Matemática, pautados em Silver, Chica, Boavida et al., Dante e D'amore; iii) estudos conceituais sobre multiplicação e divisão, pautados em Vergnaud; iv) o ambiente de pesquisa e os sujeitos (alunos e professora) envolvidos no estudo; v) análise do livro didático "Matemática", de autoria de Luiz Roberto Dante, publicado em 2014 pela editora Ática, em sua segunda edição, utilizado pela professora nas aulas de matemática, com relação à presença da prática de Formulação de Problemas e abordagens do ensino de multiplicação e divisão (Abordagem Conceitual e Metodológica) e vi) resultados de observações em classe referente à presença da prática de Formulação de Problemas nas aulas de matemática e abordagem do ensino (Dimensão Didática e Epistemológica) de multiplicação e divisão. Nessa fase, respondemos nosso primeiro objetivo específico que foi verificar como a Formulação de Problemas e o ensino de multiplicação e divisão eram abordados em livros didáticos e em aulas de matemática.

No terceiro capítulo, nomeado de "Segunda fase: concepções e análise a priori", aperfeiçoamos nossas concepções sobre os dados que analisamos na fase anterior, bem como definimos as variáveis que seriam consideradas na construção das propostas didáticas de Formulação de Problemas, escolhendo as variáveis macrodidáticas ou globais, relativas à organização da engenharia como um todo, e as variáveis microdidáticas e microdidáticas ao planejamento específico de cada proposta de ensino. Foram construídas (em conjunto com a professora regente) cinco propostas de Formulação de Problemas, em formato de histórias, que foram utilizadas para discutir multiplicação e divisão no Campo Conceitual Multiplicativo, a saber: i) A compra misteriosa; ii) A receita de sorvete; iii) Um passeio à lanchonete; iv) ...Vezes mais...Vezes menos e v) Um dever de casa desafiador. Para cada uma 
delas, foram elaboradas as análises a priori, categorizadas em três dimensões: i) Dimensão Didática; ii) Dimensão Epistemológica e iii) Outras Especificações.

No quarto capítulo, denominado de "Terceira fase: aplicação de uma sequência de atividades", direcionamos a aplicação das atividades produzidas na segunda fase e a coleta de dados para a análise a posteriori, momento esse em que os estudantes desenvolveram as atividades de Formulação de Problemas.

No quinto capítulo, designado de "Quarta fase: análise a posteriori e avaliação", realizamos o confronto entre a análise a priori e a posteriori. Além disso, realizamos uma entrevista com a professora regente em busca de evidências sobre novas aprendizagens relativas à (re)construção de conhecimento sobre a Formulação de Problemas, e dois grupos focais com os estudantes, a fim de conhecermos seus olhares para a prática de Formulação de Problema, bem como qual importância eles davam em resolver os seus próprios problemas. Nessa fase, respondemos nossos segundo e terceiro objetivos específicos que foram, respectivamente, analisar contribuições de atividades de Formulação de Problemas para o ensino de multiplicação e divisão e identificar algumas contribuições da Formulação de Problemas no ensino de matemática, na perspectiva da professora e dos alunos.

No sexto capítulo, chamado de "Produto educacional", detalhamos o produto educacional oriundo da pesquisa, destacando seus aspectos estruturais. Trata-se de um Paradidático com as atividades desenvolvidas e validadas no decorrer da pesquisa.

Sendo assim, constatamos que as propostas de Formulação de Problemas apresentaram potencial educativo à medida que possibilitaram a Formulação de Problemas envolvendo multiplicação e divisão, cujas produções carregaram aspectos conceituais matemáticos e motivacionais (situações cotidianas próximas dos estudantes) para o ensino e aprendizagem dessas operações, contribuindo para gerar motivação na resolução de seus próprios problemas de matemática.

Palavras-Chave: Formulação de Problemas. Ensino de Multiplicação e Divisão. Campo Conceitual Multiplicativo. Engenharia Didática.

Recebido em 06 de setembro de 2020. Aprovado em 19 de março de 2021. 